\title{
Two-stage mixotrophic cultivation for enhancing the biomass and lipid productivity of Chlorella vulgaris
}

\author{
Hongwu Cui ${ }^{1}$, Fanping Meng ${ }^{1,3^{*}}$, Feng Li ${ }^{2}$, Yuejie Wang ${ }^{1}$, Weiyan Duan ${ }^{1}$ and Yichen Lin ${ }^{1}$
}

\begin{abstract}
This study proposes a two-stage mixotrophic process for cultivating Chlorella vulgaris. Heterotrophic growth is the dominant step in Phase I (to increase microalgal biomass) and photoautotrophic growth occurs in Phase II (to improve biomass concentration and lipid production). The results show that the addition of the low-cost antioxidant sodium erythorbate $\left(8 \mathrm{~g} \mathrm{~L}^{-1}\right)$ significantly accelerates the growth of microalgae in the first stage with air aeration. Furthermore, a higher $\mathrm{CO}_{2}$ fixation rate was obtained in the second stage (at least $344.32 \mathrm{mg} \mathrm{CO}_{2} \mathrm{~L}^{-1}$ day ${ }^{-1}$ ) with $10 \% \mathrm{CO}_{2}$ aeration. This approximately corresponds to an increase of $177 \%$ over simple photoautotrophic cultivation with $10 \% \mathrm{CO}_{2}$ aeration during the whole period. The two-stage cultivation strategy achieved a maximum $\mathrm{C}$. vulgaris biomass concentration of $3.45 \mathrm{~g} \mathrm{~L}^{-1}$ and lipid productivity of $43.70 \mathrm{mg} \mathrm{L}^{-1}$ day $^{-1}$, which are 1.85 and 1.64 times those arising due to simple photoautotrophy, respectively. Moreover, an analysis of the product's fatty acid profile indicates that C. vulgaris might be an ideal candidate for two-stage mixotrophic cultivation of a renewable biomass for use in biodiesel applications. Another interesting point to note from the study is that it is an insufficiency of $\mathrm{N}$ and $\mathrm{CO}_{2}$ that probably limits the further growth of C. vulgaris.
\end{abstract}

Keywords: Chlorella vulgaris, Biomass, Lipid productivity, Two-stage cultivation, Fatty acid component

\section{Introduction}

The rapid development of human society and the inexpedient consumption of fossil fuels have caused an energy crisis. At the same time, huge amounts of greenhouse gases have been emitted into the atmosphere, which have induced unexpected climate changes and global warming. Among these greenhouse gases, carbon dioxide $\left(\mathrm{CO}_{2}\right)$ is the primary contributor to global warming, accounting for 52\% (Wilbanks and Fernandez 2014). On June 5, 2017, the global monthly mean $\mathrm{CO}_{2}$ concentration reached $406.05 \mathrm{ppm}$, which is much higher than the $280 \mathrm{ppm}$ level encountered before the Industrial Revolution (ESRL 2017). The development of cost-effective technologies for achieving $\mathrm{CO}_{2}$ fixation is therefore one

\footnotetext{
*Correspondence: mengfanping@ouc.edu.cn

${ }^{3}$ Department of Environmental Science and Engineering, Ocean University of China, No. 238, Songling Road, Qingdao 266100, China Full list of author information is available at the end of the article
}

of the major challenges that we are faced with today (Kaiwan-arporn et al. 2012).

Technologies for the sequestration and storage of $\mathrm{CO}_{2}$, e.g. mineral carbonation and biological fixation by plants and algae have already been developed (ToledoCervantes et al. 2013). Microalgae are the fastest growing plants on earth (able to grow 10-50 times faster than terrestrial plants) and also have a very high $\mathrm{CO}_{2}$ fixation rate (Chen et al. 2011). At the same time, microalgae constitute a source of many high-value products, e.g. biofuels, food additives, polyunsaturated fatty acids, natural colorants, health-care products, and so on. So it is generally accepted that the combination of $\mathrm{CO}_{2}$ bio-fixation and biofuel production using microalgae is a promising way of realizing a sustainable method of $\mathrm{CO}_{2}$ mitigation (Toledo-Cervantes et al. 2013). Indeed, the biodiesels that are obtained via transesterification of the lipids from microalgae have recently received widespread attention because of their non-toxicity, renewability, and environmental friendliness (Yilancioglu et al. 2014). Oleaginous 
microalgae potentially have great advantages as promising resources for biodiesel production: high photosynthetic efficiency, high lipid productivity per unit of land, high growth rate, and they can also be grown in a wide range of environments (Rawat et al. 2013; Wang et al. 2008). Nevertheless, the scalability, sustainability, and cost-efficiency of using large-scale algae cultivation for biodiesel production remain unproven and somewhat controversial (Toledo-Cervantes et al. 2013). The major issues to resolve are finding a cultivation system that has high cell density with optimum lipid content that can also be carried out on a suitably large scale (Huerlimann et al. 2010).

Currently, photoautotrophic cultivation is the most commonly-used strategy for cultivating microalgae (as most microalgae are autotrophs). However, some microalgae can grow with organic carbon substances simultaneously. It is well known that cultivating microalgae in heterotrophic or mixotrophic conditions is an effective way of increasing cell density, as well as lipid content, when organic carbons, e.g. sugars and organic acids, are used as carbon sources (Najafabadi et al. 2015). Studies have shown that some microalgae have higher growth rates and biomass yields (and even lipid content) under mixotrophic compared to photoautotrophic conditions. Bhatnagar et al. (2010) have investigated the mixotrophic cultivation of $C$. minutissima. They concluded that mixotrophic growth results in the production of 4.43 times more biomass than photoautotrophy if $10 \mathrm{~g} \mathrm{~L}^{-1}$ glucose is added. Similarly, the lipid content under mixotrophic conditions was 1.18 times that under photoautotrophic conditions. Liang et al. (2009) studied the growth rate and lipid content of C. vulgaris (UTEX 259) cultivated under mixotrophic conditions and showed that the biomass concentration due to mixotrophic growth reached $1.70 \mathrm{~g} \mathrm{~L}^{-1}$. This should be compared to $0.25 \mathrm{~g} \mathrm{~L}^{-1}$ produced by photoautotrophic growth with the same concentration of glucose added. Conversely, the lipid content of C. vulgaris in the phototrophy treatment reached up to $38 \%$ compared to $21 \%$ in the mixotrophy treatment. Furthermore, research has revealed that the antioxidant sodium erythorbate $(\mathrm{NaE})$ has a better promotional effect on the growth of Chlorella vulgaris than glucose (Cui et al. 2017).

Therefore, in this study, a new two-stage mixotrophic cultivation process is proposed to cultivate C. vulgaris in order to enhance biomass concentration and lipid production. The method involves the addition of $\mathrm{NaE}$ in the first stage to promote a rapid growth in biomass. In the second stage, higher $\mathrm{CO}_{2}$ fixation rates and lipid productivities are obtained using $10 \% \mathrm{CO}_{2}$ aeration. Finally, biomass productivity, $\mathrm{CO}_{2}$ bio-fixation rate, and the fatty acid (FA) profile of the microalgal lipids were analyzed to evaluate the effectiveness of the new strategy and assess its potential application to biodiesel production.

\section{Materials and methods \\ The microalgal strain and culture medium}

The microalgae strain Chlorella vulgaris FACHB-960 was employed in this study. It was acquired from the Institute of Hydrobiology (FACHB-collection), which is part of the Chinese Academy of Sciences in Wuhan, China. The microalgae were pre-cultured in 500-mL Erlenmeyer flasks using Bristol's solution (Cheng et al. 2013). Continuous illumination $\left(60 \mu \mathrm{mol}\right.$ photons $\left.\mathrm{m}^{-2} \mathrm{~s}^{-1}\right)$ was applied for 5 days using cool-white fluorescent tubes (F25T8/TL 950, Philips Ltd., The Netherlands) at $25{ }^{\circ} \mathrm{C}$. The Erlenmeyer flasks were shaken six times daily by hand to avoid sticking. Algal cells in the exponential growth phase were used for the following experiments.

\section{Photobioreactors and chemicals}

The laboratory-scale airlift photobioreactor (PBR) used for C. vulgaris cultivation is shown in Fig. 1. The PBR has a working volume of $3 \mathrm{~L}$ and features a sampling point and gas inlet/outlet tubes (the former connected to the aeration apparatus). Magnetic stirrers (JB-2A, Shanghai Rex Instrument Factory, China) were positioned under the flasks to stop the algal cells sticking.

The $\mathrm{NaE}\left(\mathrm{C}_{6} \mathrm{H}_{7} \mathrm{NaO}_{6} \cdot \mathrm{H}_{2} \mathrm{O}\right.$, purity $\left.\geq 98.0 \%\right)$ used was obtained from the Tokyo Chemical Industry Co., Ltd. (Shanghai, China) as a yellowish powder with a solubility in water of $17 \mathrm{~g}$ per $100 \mathrm{~mL}$.

\section{Experimental procedure}

Chlorella vulgaris cells (in the exponential phase of growth) were separately inoculated into 12 PBRs with $3 \mathrm{~L}$ Bristol's solution, yielding an initial cell density of $5 \times 10^{6}$ cells $\mathrm{mL}^{-1}$ (an initial optical density $\mathrm{OD}_{680}$ of 0.25 ). The PBRs were divided into 4 groups: a mixotrophic group ('MX'), mixotrophic group with nitrogen deficiency ('MX-N'), mixotrophic group with $\mathrm{CO}_{2}$ deficiency ('MX$\mathrm{C}^{\prime}$ ), and photoautotrophic group ('PA'). Each group consists of 3 replications. The PBRs were illuminated for $24 \mathrm{~h}$ $\left(120 \mu \mathrm{mol}\right.$ photons $\left.\mathrm{m}^{-2} \mathrm{~s}^{-1}\right)$ using fluorescent tubes in light incubators (GXZ-280B, Ningbo Jiangnan Instrument Factory, China) at $25^{\circ} \mathrm{C}$. Details of the experimental conditions employed are given in Table 1.

\section{Phase I-mixotrophic cultivation to improve biomass}

Phase I was carried out to rapidly improve the biomass of C. vulgaris via mixotrophic cultivation. A previous study has shown that maximum C. vulgaris biomass is obtained if an $\mathrm{NaE}$ dosage of $8.0 \mathrm{~g} \mathrm{~L}^{-1}$ is used (Cui et al. 2017). Hence, $24.0 \mathrm{~g}$ solid $\mathrm{NaE}$ was added into $3 \mathrm{~L}$ Bristol's solution of nine PBRs at the beginning of the cultivation 


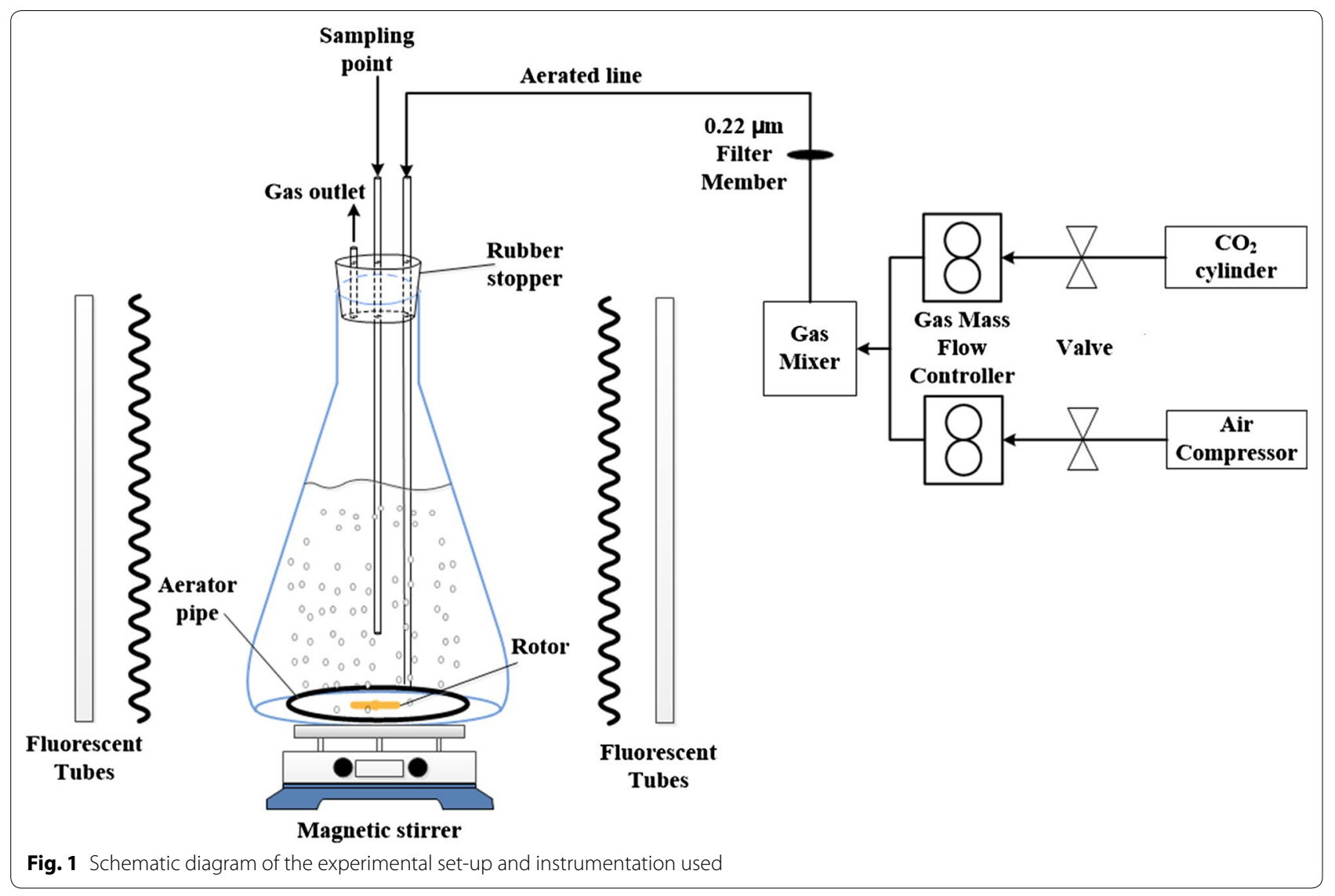

Table 1 The conditions used in the two-stage $C$. vulgaris cultivation experiments

\begin{tabular}{|c|c|c|c|c|c|c|}
\hline \multirow[t]{2}{*}{ Group } & \multicolumn{3}{|l|}{ Phase I (0-9 days) } & \multicolumn{3}{|l|}{ Phase II (10-18 days) } \\
\hline & $\begin{array}{l}\text { NaE concentration } \\
\left(\mathrm{g} \mathrm{L}^{-1}\right)\end{array}$ & Aeration ${ }^{\mathrm{a}}$ medium & $\begin{array}{l}\text { Nutrient }{ }^{\mathrm{b}} \text { added } \\
\text { on day } 4(\mathrm{~mL})\end{array}$ & Added carbon source & Aeration ${ }^{\mathrm{a}}$ medium & $\begin{array}{l}\text { Nutrient }{ }^{\mathrm{b}} \text { added } \\
\text { on day } 9(\mathrm{~mL})\end{array}$ \\
\hline$M X$ & 8 & Air & 6 & - & $10 \% \mathrm{CO}_{2}(\mathrm{v} / \mathrm{v})$ & 30 \\
\hline MX-N & 8 & Air & 6 & - & $10 \% \mathrm{CO}_{2}(\mathrm{v} / \mathrm{v})$ & 0 \\
\hline$M X-C$ & 8 & Air & 6 & - & Air & 30 \\
\hline PA & 0 & $10 \% \mathrm{CO}_{2}(\mathrm{v} / \mathrm{v})$ & 6 & - & $10 \% \mathrm{CO}_{2}(\mathrm{v} / \mathrm{v})$ & 0 \\
\hline
\end{tabular}

- , no action

a Using a flow rate of $60 \mathrm{~mL} \mathrm{\textrm {min } ^ { - 1 }}$

b $\mathrm{NaNO}_{3}$ of concentration $250 \mathrm{~g} \mathrm{~L}^{-1}$

process (i.e. groups $\mathrm{MX}, \mathrm{MX}-\mathrm{N}$, and $\mathrm{MX}-\mathrm{C}$ ), achieving $8.0 \mathrm{~g} \mathrm{~L}^{-1}$ of $\mathrm{NaE}$ for each PBR. These were aerated for 9 days (using $60 \mathrm{~mL} \mathrm{~min}^{-1}$ air). The control group PA was continuously aerated with $10 \% \mathrm{CO}_{2}$ (v/v) during the whole of the Phase I cultivation stage (using the same flow rate used in the other flasks). According to some pre-test results (data not shown), nitrogen deficiency is the primary nutrient limitation of Bristol's medium. As a result, $6 \mathrm{~mL}$ of $250 \mathrm{~g} \mathrm{~L}^{-1} \mathrm{NaNO}_{3}$ (a component of
Bristol's medium) was injected into each of the 12 PBRs on day 4.

\section{Phase Il-mixotrophic cultivation to improve $\mathrm{CO}_{2}$ bio-fixation and lipid productivity}

The purpose of Phase II is to investigate the effect on biomass, lipid productivity, and fatty acid composition of the C. vulgaris of changing the aeration medium from air to $10 \% \mathrm{CO}_{2}$ (assuming there is sufficient nitrogen available). 
At the beginning of Phase II (day 10), $30 \mathrm{~mL}$ of $250 \mathrm{~g} \mathrm{~L}^{-1}$ $\mathrm{NaNO}_{3}$ was added to groups MX and MX-C, and the aeration medium was changed from air to $10 \% \mathrm{CO}_{2}$ at the same time for groups MX and MX-N until the end of the cultivation procedure.

\section{Analytical methods Optical density and $\mathrm{pH}$}

The algal solutions were sampled via the sampling points in order for certain indices to be measured. The value of the optical density (OD) of each culture was measured every day using a UV-Vis spectrophotometer (model TU-1810, Persee, China). The absorbance at $680 \mathrm{~nm}$ was determined after the sample was appropriately diluted with deionized water to make the absorbance less than 1.0. Another $5 \mathrm{~mL}$ algal solution was sampled and centrifuged each day to allow the solution's $\mathrm{pH}$ value to be determined (at the same height in each suspension) using a pH electrode connected to a $\mathrm{pH}$ meter (PHS-3C, Shanghai LIDA Instrument Factory, China).

\section{Biomass, biomass productivity, carbon content, and $\mathrm{CO}_{2}$ fixation rate}

The biomass concentration was estimated by filtering a sample through a $0.45 \mu \mathrm{m}$ cellulose acetate membrane and drying it at $105{ }^{\circ} \mathrm{C}$ to constant mass. Biomass determination was carried at the end of Phases I and II.

The biomass productivity, $P\left(\mathrm{mg} \mathrm{L}^{-1}\right.$ day $\left.^{-1}\right)$, is defined as:

$$
P=\frac{X_{t}-X_{0}}{t}
$$

where $X_{0}$ is the initial biomass concentration $\left(\mathrm{mg} \mathrm{L}^{-1}\right)$ and $X_{t}$ is the biomass concentration at time $t$ (day).

The carbon content of the biomass was determined using a CHNS analyzer (Series II $2400 \mathrm{CHNS} / \mathrm{O}$ Perkin Elmer, Boston, USA). The $\mathrm{CO}_{2}$ fixation rate, $P_{\mathrm{CO}_{2}}$, can subsequently be calculated using the expression (ToledoCervantes et al. 2013):

$$
P_{\mathrm{CO}_{2}}=C_{\mathrm{C}} P\left(\frac{M_{\mathrm{CO}_{2}}}{M_{\mathrm{C}}}\right)
$$

where $M_{\mathrm{C}}$ is the atomic weight of carbon, $M_{\mathrm{CO}_{2}}$ is the molecular weight of $\mathrm{CO}_{2}$, and $C_{\mathrm{C}}$ is the carbon content of the biomass $\left(\mathrm{g}_{\mathrm{C}} / \mathrm{g}_{\text {biomass }}\right)$.

\section{$\mathrm{NO}_{3}-\mathrm{N}$, total phosphorus, and total organic carbon concentrations}

To determine the water quality, a sample of microalgae culture was centrifuged (at $4000 \mathrm{~g}$ for $10 \mathrm{~min}$ ) and the supernatant filtered through a $0.45 \mu \mathrm{m}$ membrane. This was used to determine the $\mathrm{NO}_{3}-\mathrm{N}$ and total phosphorus (TP) content on days $0,6,16$, and 18 , according to the standard testing methods suggested by the Chinese state (Xu et al. 2015).

The total organic carbon (TOC) concentration was also determined using a total organic carbon analyzer (TOC-Vcpn, Shimadzu, Japan) after a culture sample was centrifuged (at $4000 \mathrm{~g}$ for $10 \mathrm{~min}$ ) and filtered through a $0.45 \mu \mathrm{m}$ glass-fiber filter membrane (on days $0,9,16$, and 18). Potassium hydrogen phthalate was used as a standard to calculate the TOC concentration $\left(\mathrm{mg} \mathrm{L}^{-1}\right)$.

\section{Lipid content, lipid productivity, and fatty acid component analysis}

The total lipid content was extracted using an organic solvent and determined gravimetrically. The microalgal solution was centrifuged (at $4000 \mathrm{~g}$ for $10 \mathrm{~min}$ ) at $4{ }^{\circ} \mathrm{C}$. The resulting microalgal pellet was washed twice with distilled water, centrifuged to remove salts, and freeze dried at $-50{ }^{\circ} \mathrm{C}$. Lipids were extracted from the dry biomass pellets using a modified solvent-based method derived from the work of Bingh and Dyer (1959). In brief, $100 \mathrm{mg}$ of dried algal powder was transferred to $7.6 \mathrm{~mL}$ of a mixture of chloroform/methanol/water (2.5/5/2 $\mathrm{v} / \mathrm{v}$ ) and homogenized (Ultrasonic Homogenizer JY92II, SCIENTZ, China) for $120 \mathrm{~s}$ (700 W, $5 \mathrm{~s}$ working, $5 \mathrm{~s}$ resting). The mixture was then left at room temperature for $24 \mathrm{~h}$. After adding $1 \mathrm{~mL}$ of chloroform and $1 \mathrm{~mL}$ of water, the mixture was centrifuged (at $4000 g$ for $10 \mathrm{~min}$ ) to form three layers. The lowermost (organic) layer was carefully collected in a pre-weighed $10 \mathrm{~mL}$ glass tube and the organic solvent removed using a nitrogen evaporator. The entire extraction process was repeated twice. The total percentage lipid content, $\eta$, was subsequently calculated according to:

$$
\eta=\frac{W_{1}}{W_{0}} \times 100 \%,
$$

where $W_{1}$ and $W_{0}$ are the lipid mass $(\mathrm{g})$ and dry cell mass $(\mathrm{g})$, respectively.The lipid productivity, $L P\left(\mathrm{mg} \mathrm{L}^{-1}\right.$ day $^{-1}$ ), of the microalgae could then be deduced using the expression:

$$
L P=P \eta \text {. }
$$

The FA composition of the lipids was determined via gas chromatography-mass spectrometry (GC-MS) analysis (Kebelmann et al. 2013). Freeze-dried algae samples $(20-50 \mathrm{mg})$ were weighed into clean glass centrifugal tubes $(10 \mathrm{~mL})$ and $1 \mathrm{~mL}$ of saturated $\mathrm{KOH} / \mathrm{CH}_{3} \mathrm{OH}$ solution added. Transesterification was carried out in a water bath (at $80{ }^{\circ} \mathrm{C}$ for $1 \mathrm{~h}$ ). After cooling, $3 \mathrm{~mL}$ of distilled water and $2 \mathrm{~mL}$ of hexane were added and the mixture vortexed for $2 \mathrm{~min}$. The upper phase containing the FAs was carefully collected and analyzed via GC-MS (7890A/5975C, Agilent, USA) using a DB-5 ms 
chromatographic column $(50 \mathrm{~m} \times 250 \mu \mathrm{m} \times 0.25 \mu \mathrm{m})$. The oven temperature was set to $80{ }^{\circ} \mathrm{C}$, then raised to $300{ }^{\circ} \mathrm{C}$ at a rate $10{ }^{\circ} \mathrm{C} / \mathrm{min}$, and held at $300{ }^{\circ} \mathrm{C}$ for $5 \mathrm{~min}$; the injector temperature was set to $300{ }^{\circ} \mathrm{C}$. The helium carrier gas was supplied at a flow rate of $1 \mathrm{~mL} \mathrm{~min}{ }^{-1}$. All the analyses were carried out in triplicate and the reported values correspond to their averages.

\section{Statistical analysis}

Statistical analysis was performed using the SPSS 17.0 software package (SPSS Co., USA). For each treatment, the means and standard deviations were calculated using the three biological replicates.

\section{Results}

\section{Microalgal growth and $\mathrm{pH}$ variation}

Figure 2a presents the growth curves obtained for the 4 groups during the cultivation period. The addition of $\mathrm{NaE}$ can be clearly seen to have significantly accelerated the growth of $C$. vulgaris in Phase I as the amount of $C$. vulgaris in MX, MX-N, and MX-C groups increased at a much faster rate from day 1 (with no signs of a phase lag) compared to group PA. A stationary phase was observed on day 8 in the three mixotrophic groups in Phase I in which the $\mathrm{OD}_{680}$ value remained around $4.8(\sim 1.8$ times that observed in the control PA).

The change in conditions on day 9 lead to the growth curves of the three mixotrophic groups in Phase II exhibiting obvious differences (although their OD values remained above those of the photoautotrophic group in each case). Different levels of decline in growth of the MX, MX-N, and MX-C groups were observed on day 10. After a slight drop, and the changes in the MX-N and MX-C groups became much less obvious throughout the rest of the cultivation period. In contrast, sustained growth continued to be observed in the MX group from day 11 . At the end of the cultivation period, the $\mathrm{OD}_{680}$ values of the 4 groups were ranked, in descending order, as: $\mathrm{MX}(6.22)>\mathrm{MX}-\mathrm{C}(4.20)>\mathrm{MX}-\mathrm{N}(3.38)>\mathrm{PA}$ (2.51).

Plots of the changes in the $\mathrm{pH}$ values of the culture mixture are shown in Fig. 2b. A rapid decline in $\mathrm{pH}$ can be seen to occur at the beginning of Phase I in each group. The decline lasted for about three days in the three mixotrophic groups and just one day in the PA group (falling to about 5.73 and 5.86, respectively). After falling, the $\mathrm{pH}$ values in the MX, MX-N, and MX-C groups underwent dramatic increases which continued up to the end of Phase I. In one group, $\mathrm{MX}-\mathrm{C}$, the rise in $\mathrm{pH}$ continued right up to the end of the cultivation period (the final value was 8.62 on day 18). In contrast, sharp drops $(\sim 0.98)$ were observed in the $\mathrm{pH}$ values of $\mathrm{MX}$ and MX-N on day 10. After this drop, their $\mathrm{pH}$ values underwent slight increases to the end of the cultivation period,
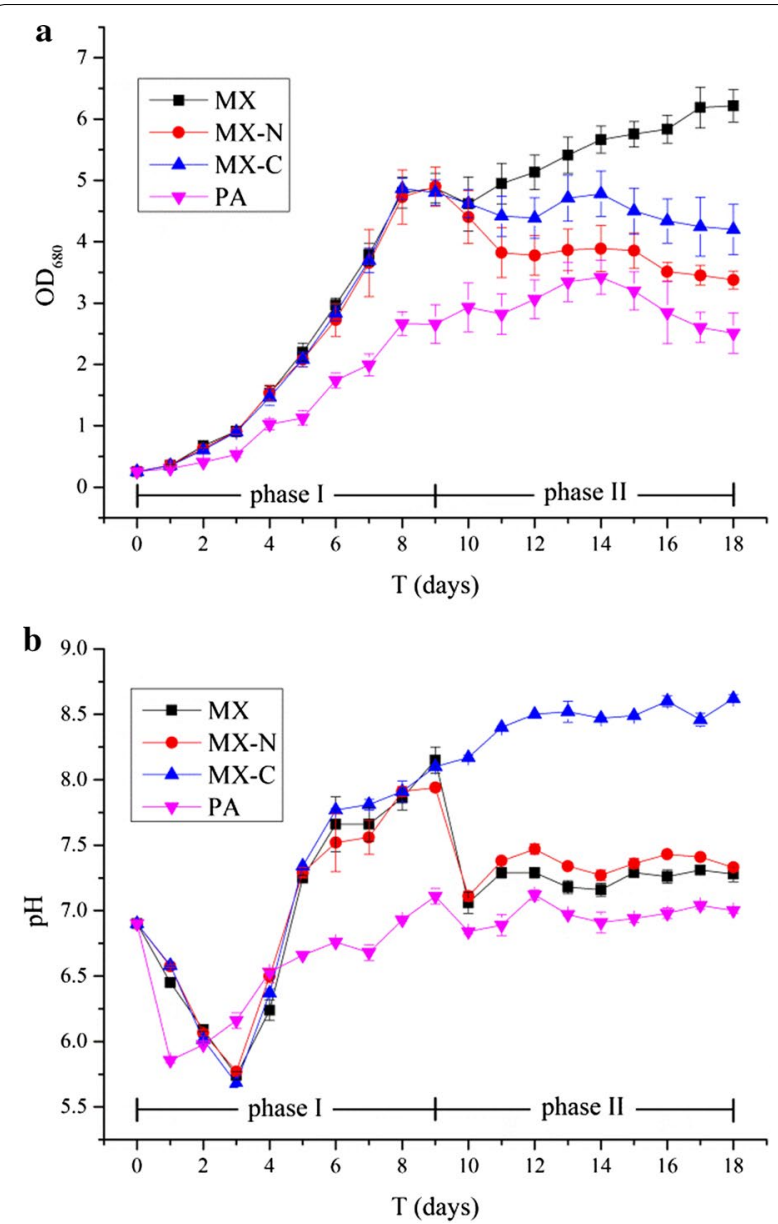

Fig. 2 Plots showing the time-dependent changes observed in: a the growth of $C$. vulgaris, and $\mathbf{b} \mathrm{pH}$ of the culture during the cultivation period for the four treatment groups. Experiments were conducted in triplicate, and the results shown are the means (with standard deviations, $n=3$ )

reaching $7.28(\mathrm{MX})$ and $7.33(\mathrm{MX}-\mathrm{N})$ on day 18. However, the $\mathrm{pH}$ value in the PA group of samples 'rebounded' from the second day onwards, reaching 7.11 at the end of Phase I, and then remaining mostly unchanged (with some fluctuation) until the end of the experiment.

\section{Nutrient and TOC variation}

The results obtained for the residual $\mathrm{NO}_{3}-\mathrm{N}, \mathrm{TP}$, and TOC concentrations during the two phases are shown in Table 2. We recall that $6 \mathrm{~mL}$ of $250 \mathrm{~g} \mathrm{~L}^{-1} \mathrm{NaNO}_{3}$ was added to each PBR on day 4-this corresponds to a concentration increase of $\sim 82.35 \mathrm{mg} \mathrm{L}^{-1} \mathrm{NO}_{3}-\mathrm{N}$ for each vessel (indicated in the table using the notation ' +82.35 ' on day 4 , assuming there was $3 \mathrm{~L}$ of liquid in each PBR).

Table 2 shows that there was a much higher utilization of $\mathrm{NO}_{3}-\mathrm{N}$ and TP in the three mixotrophic groups during the first 6 days of Phase I compared to the PA group. 


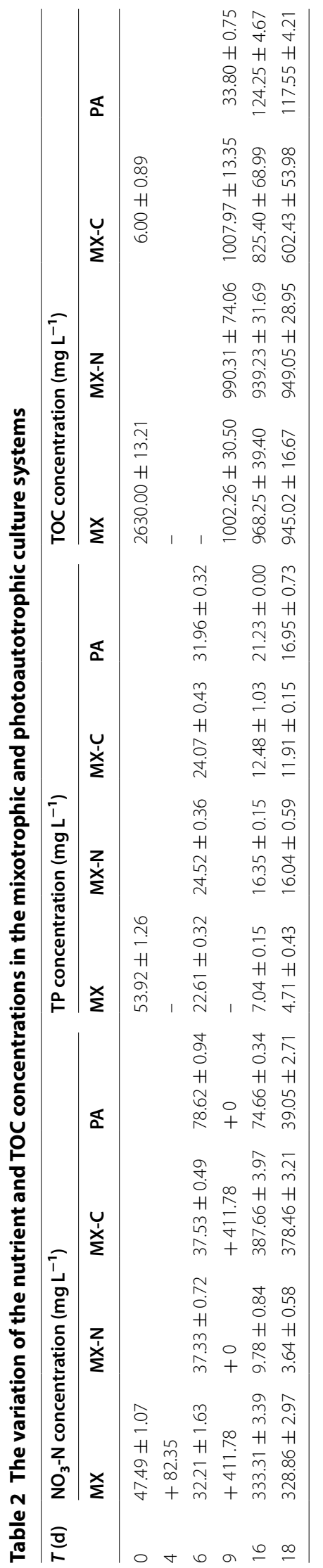


On average, the three mixotrophic groups consumed about $94.15 \mathrm{mg} \mathrm{L}^{-1}$ of $\mathrm{NO}_{3}-\mathrm{N}$ which is much higher than the initial $\mathrm{NO}_{3}-\mathrm{N}$ concentration $\left(47.49 \mathrm{mg} \mathrm{L}^{-1}\right)$. However, $\mathrm{NO}_{3}-\mathrm{N}$ and $\mathrm{TP}$ consumption in the PA group was much less (so the concentrations of these components were about 2.20 and 1.35 times those in the mixotrophic groups, respectively, on average).

As a large amount of $\mathrm{NO}_{3}-\mathrm{N}$ was consumed in the $\mathrm{MX}$, MX-N, and MX-C flasks, the nitrogen content in some of these flasks (MX and MX-C) were further enhanced at the beginning of Phase II (by adding $30 \mathrm{~mL}$ of $250 \mathrm{~g} \mathrm{~L}^{-1}$ $\mathrm{NaNO}_{3}$, corresponding to a concentration increase of about $411.8 \mathrm{mg} \mathrm{L}^{-1} \mathrm{NO}_{3}-\mathrm{N}$ in each flask). None was added to the MX-N flasks as these are intended to serve as 'nitrogen-starved' controls. The $\mathrm{NO}_{3}-\mathrm{N}$ concentrations at the end of Phase II were about 328.86, 3.64, 378.46, and $39.05 \mathrm{mg} \mathrm{L}^{-1}$ in groups MX, MX-N, MX-C, and PA respectively (Table 2 ). Clearly, there were high concentrations of $\mathrm{NO}_{3}-\mathrm{N}$ left in the flasks in groups $\mathrm{MX}$ and MX-C at the end of Phase II, but very little was left in the nitrogen-starved MX-N flasks. However, the TP concentrations in the MX and MX-C flasks (i.e. with added $\mathrm{NaNO}_{3}$ ) were relatively low at the end of the cultivation period (see Table 2), especially in the MX group where the TP concentration was found to correspond to the lowest value measured: $4.71 \mathrm{mg} \mathrm{L}^{-1}$.

Due to the addition of the NaE, the initial TOC concentration in the mixotrophic groups was $2630.0 \mathrm{mg} \mathrm{L}^{-1}$. However, their TOC values declined significantly by the end of Phase I, decreasing to $\sim 1000 \mathrm{mg} \mathrm{L}^{-1}$ in each case (a utilization rate of $\sim 62 \%$ ). In contrast, the TOC utilization rate varied markedly in Phase II due to the changes made in the culturing conditions used. The TOC concentrations at the end of the experiment corresponded to 945.02, 949.05, and 602.43 $\mathrm{mg} \mathrm{L}^{-1}$ in groups MX, MX-N, and MX-C, respectively (utilization rates of 2.2, 1.6, and $15.4 \%$, respectively). Interestingly, the almost negligible TOC concentration in the PA group measured at the beginning of Phase $\mathrm{I}\left(6.00 \mathrm{mg} \mathrm{L}^{-1}\right)$ was increased to $117.55 \mathrm{mg} \mathrm{L}^{-1}$ by the end of the cultivation period.

\section{Biomass concentration and productivity}

The biomass results are shown in Table 3. Clearly, the biomass concentrations in the three mixotrophic groups were much higher (by roughly 164\%) than that in the photoautotrophic group at the end of Phase I. Furthermore, the average biomass productivity in the mixotrophic groups was $0.18 \mathrm{~g} \mathrm{~L}^{-1}$ day $^{-1}$ compared to $0.11 \mathrm{~g} \mathrm{~L}^{-1}$ day $^{-1}$ in the PA group.

In Phase II, the biomass variation was quite different in each group. All of the groups increased except for MX-N (see Table 3). In this nitrogen-starved group, the biomass concentration declined by $0.13 \mathrm{~g} \mathrm{~L}^{-1}$ during Phase II (although a slight increase was observed from day 9 to 14-see Fig. 2a). The maximum final biomass concentration was obtained in group MX and corresponded to $3.45 \mathrm{~g} \mathrm{~L}^{-1}$ (see Table 3). This figure is 136, 70.8, and $185 \%$ greater than the biomasses in the MX-N, MX-C, and PA groups, respectively. A rise in biomass productivity in Phase II was also found only in the MX case. In contrast, the biomass productivity in the MX-C and PA groups declined significantly in Phase II (Table 3 ).

\section{Lipid content, lipid productivity, and fatty acid composition}

The two-stage procedure was carried out in order to increase lipid productivity. The results obtained for lipid production are also shown in Table 3. The lipid contents of the four groups, at the end of Phase II, were found to be of the order of $20-25 \%$ of the dry cell weight. The highest lipid content (24.6\%) occurred in the PA group but, unfortunately, this group also has the lowest biomass productivity. Hence, PA has the smallest final lipid productivity value $\left(16.56 \mathrm{mg} \mathrm{L}^{-1}\right.$ day $\left.^{-1}\right)$. The lipid content of the MX group (22.8\%) is close to the average level of the four groups, but its lipid productivity is the largest observed (131.0, 92.9, and 163.9\% larger than that produced in the MX-N, MX-C, and PA groups, respectively) due to the greater amount of biomass produced.

The FA compositions at the end of Phase II are presented in Table 4. As can be observed, the primary FA

Table 3 Comparison of the change in biomass concentration, biomass productivity, lipid content, lipid production, and lipid productivity of $C$. vulgaris in the four culture systems

\begin{tabular}{lccrr}
\hline & MX & MX-N & MX-C & PA \\
\hline Change in biomass concentration in Phase I $\left(\mathrm{g} \mathrm{L}^{-1}\right)$ & $1.66 \pm 0.05$ & $1.59 \pm 0.08$ & $1.62 \pm 0.06$ & $0.99 \pm 0.04$ \\
Change in biomass concentration in Phase II $\left(\mathrm{g} \mathrm{L}^{-1}\right)$ & $1.79 \pm 0.04$ & $-0.13 \pm 0.04$ & $0.40 \pm 0.06$ & $0.22 \pm 0.04$ \\
Biomass productivity in Phase I $\left(\mathrm{g} \mathrm{L}^{-1}\right.$ day $\left.^{-1}\right)$ & $0.18 \pm 0.01$ & $0.18 \pm 0.01$ & $0.18 \pm 0.01$ & $0.11 \pm 0.00$ \\
Biomass productivity in Phase II $\left(\mathrm{g} \mathrm{L}^{-1}\right.$ day $\left.^{-1}\right)$ & $0.20 \pm 0.00$ & - & $0.044 \pm 0.01$ & $0.024 \pm 0.00$ \\
Final lipid content, $\eta$ (\%) & $22.8 \pm 0.8$ & $23.3 \pm 1.1$ & $20.2 \pm 1.2$ & $24.6 \pm 0.9$ \\
Final lipid production ( $\mathrm{mg} \mathrm{L}^{-1}$ ) & $786.60 \pm 27.21$ & $340.47 \pm 21.40$ & $407.83 \pm 21.55$ & $298.02 \pm 25.61$ \\
Final lipid productivity $\left(\mathrm{mg} \mathrm{L}^{-1}\right.$ day $\left.^{-1}\right)$ & $43.70 \pm 1.51$ & $18.92 \pm 1.19$ & $22.66 \pm 1.20$ & $16.56 \pm 1.42$ \\
\hline
\end{tabular}

' - 'is used to imply the numerical calculation is meaningless here 
Table 4 Relative abundances of various fatty acids at the end of the cultivation period (\%)

\begin{tabular}{lllll}
\hline Fatty acid & MX & MX-N & MX-C & PA \\
\hline C16:0 & $28.9 \pm 0.3$ & $15.1 \pm 0.2$ & $8.7 \pm 0.2$ & $17.3 \pm 0.3$ \\
C16:1 & $25.2 \pm 0.2$ & $24.8 \pm 0.4$ & $4.7 \pm 0.2$ & $15.2 \pm 0.2$ \\
C16:2 & $5.0 \pm 0.1$ & $6.8 \pm 0.2$ & $5.1 \pm 0.1$ & $\mathrm{ND}$ \\
C16:3 & $4.0 \pm 0.0$ & $5.4 \pm 0.1$ & $5.3 \pm 0.1$ & $\mathrm{ND}$ \\
C18:0 & $0.7 \pm 0.0$ & $7.8 \pm 0.1$ & $14.6 \pm 0.4$ & $5.5 \pm 0.0$ \\
C18:1 & $5.8 \pm 0.1$ & $2.6 \pm 0.0$ & $20.6 \pm 0.3$ & $10.3 \pm 0.3$ \\
C18:2 & $2.1 \pm 0.0$ & $12.4 \pm 0.1$ & $10.5 \pm 0.1$ & $\mathrm{ND}$ \\
C18:3 & $19.8 \pm 0.2$ & $12.2 \pm 0.2$ & $10.5 \pm 0.1$ & $\mathrm{ND}$ \\
Others & $8.5 \pm 0.1$ & $13.0 \pm 0.2$ & $20.1 \pm 0.4$ & $51.8 \pm 1.2$ \\
Total saturated fatty acid & 37.7 & 25.8 & 33.6 & 66.5 \\
Monounsaturated fatty & 31.0 & 31.4 & 26.8 & 33.5 \\
$\quad$ acid & & & & \\
Polyunsaturated fatty & 31.3 & 42.8 & 39.6 & $\mathrm{ND}$ \\
$\quad$ acid & & & & \\
Total unsaturated fatty & 62.3 & 74.2 & 66.4 & 33.5 \\
$\quad$ acid & & & & \\
\hline
\end{tabular}

Italic values indicate maximum relative abundance of fatty acids in the group $N D$ not detected

components are C16:0 (palmitic acid, 28.9\%), C16:1 (palmitoleic acid, 24.82\%), C18:1 (oleic acid, 20.59\%) and C16:0 (palmitic acid, 17.26\%) for groups MX, MX-N, MX-C, and PA, respectively. The percentage total saturated fatty acid (TSFA) and monounsaturated fatty acid (MUFA) both have their maximum values in the PA group. However, no polyunsaturated fatty acids (PUFAs) were found in the PA group. In contrast, PUFAs constitute large proportions of the three mixotrophic groups (i.e. those with added $\mathrm{NaE}$ ). With respect to omega 3 (linolenic acid) and omega 6 (linoleic) FAs (also known as 'essential' FAs), these were found to be in high concentration in the three mixotrophic treatments. For omega 3, the percentage content corresponds to $19.79,12.23$, and $10.47 \%$, in MX, MX-N, and MX-C, respectively. The corresponding figures for omega 6 are 2.07, 12.38, and $10.45 \%$. C16 and C18 are the two most predominant carbon chain lengths found to occur in the FAs determined, accounting for $91.47,87$, and $79.9 \%$ of the acids in MX, MX-N, and MX-C, respectively.

\section{Discussion}

Mixotrophic cultivation is an attractive way of enhancing the concentration of algal biomasses (Yen and Chang 2013) and mode by which the microalgae can drive both photoautotrophy and heterotrophy and utilize both inorganic and organic carbon sources (Kang et al. 2004). In this study, a two-stage method of mixotrophic cultivation of C. vulgaris has been treated in detail. Phase I was used to improve the biomass concentration of the microalgae and Phase II to enhance the $\mathrm{CO}_{2}$ bio-fixation rate and lipid productivity.
By adding the natural antioxidant $\mathrm{NaE}$ and aerating the culture mixture with air in Phase I of the two-stage process, the oxidized intermediates from the $\mathrm{NaE}$ can be used by the $C$. vulgaris as organic carbon sources for mixotrophic growth (Cui et al. 2017). This is why the microalgal growth rates in the MX, MX-N, and MX-C samples were much greater than that in the PA group during the first 9 days (Fig. 2a), and why the average biomass productivity was $63.6 \%$ higher in those samples compared to the PA group (Table 3). As reported in the literature, by complementing the photoautotrophic process with organic substrates, the mixotrophic cultivation of microalgae can improve the growth rate, shorten the growth cycle, and increase biomass productivity (Park et al. 2012).

The biomass concentration of $1.66 \mathrm{~g} \mathrm{~L}^{-1}$ (day 9) achieved in this study is roughly 1.43 that of the biomass concentration of $1.16 \mathrm{~g} \mathrm{~L}^{-1}$ (day 12) reported in a previous study (Cui et al. 2017) $(p<0.05)$. In Cui et al's work, no aeration was used but the $\mathrm{NaE}$ dosage was the same $\left(8 \mathrm{~g} \mathrm{~L}^{-1}\right)$. This suggests that aeration is essential to improve the growth rate of $C$. vulgaris in a mixotrophic culture system (compared to photoheterotrophic cultivation). There are two reasons for this:

1. Aeration accelerates the oxidation of NaE. Subsequently, larger amounts of oxidative intermediate products are formed which can be utilized as organic carbon sources to facilitate mixotrophic growth of C. vulgaris. This is also illustrated by the TOC consumption data presented in Table 2. (In this work, TOC decreased by $\sim 1630 \mathrm{mg} \mathrm{L}^{-1}$ in 9 days which should be compared to a decrement of $477 \mathrm{mg} \mathrm{L}^{-1}$ in 12 days in Cui et al. 2017 study.) The observed $\mathrm{pH}$ variation may also increase the credibility of this view. Acidic intermediate products are formed during $\mathrm{NaE}$ oxidation (Cui et al. 2017) which cause the $\mathrm{pH}$ in mixotrophic culture systems to decrease for the first 3 days. These products will be subsequently taken up by the $C$. vulgaris and used for oxidative assimilation via aerobic glycolysis. This results in an increase in $\mathrm{pH}$ from day 3 onwards and a decrease in the TOC level (Fig. 2b and Table 2).

2. Aeration provides $\mathrm{O}_{2}$ which contributes to the heterotrophic (aerobic respiration) part of the mixotrophic growth process. Yen and Zhang (2011) have suggested that low dissolved oxygen levels could retard cell growth, while high levels lead to rapid cell growth and maximum dry weights in heterotrophic cultures. Yeh and Chang (2012) also made a similar observation (C. vulgaris ESP-31 cultivated in a mixotrophic culture system produces a higher biomass than that produced using a photoheterotrophic culture system). 
There was a rapid growth of $C$. vulgaris during the first 6 days (Fig. 2a). Table 2 shows that the consumption of $\mathrm{NO}_{3}-\mathrm{N}$ was $\sim 94 \mathrm{mg} \mathrm{L}^{-1}$ in the three mixotrophic groups and $\sim 51 \mathrm{mg} \mathrm{L}^{-1}$ in the photoautotrophic group. Both of these figures are larger than the initial $\mathrm{NO}_{3}-\mathrm{N}$ concentration in Bristol's medium ( $47.49 \mathrm{mg} \mathrm{L}^{-1}$ ). Thus, it was necessary to replenish the supply of nitrogen on day 4 for all of the groups. Procházková et al. (2014) reported that the most widely used nitrogen source for microalgal cultivation is nitrate and so this source was adopted here.

Table 2 also suggests that there was enough TP available during the experiment, with the smallest amount of residual TP available at the end of the cultivation period occurring in the MX group of samples (equal to $\sim 4.71 \mathrm{mg} \mathrm{L}^{-1}$ ). A general conclusion can be drawn from the molecular formula of the microalgal biomass: $\mathrm{CO}_{0.48} \mathrm{H}_{1.83} \mathrm{~N}_{0.11} \mathrm{P}_{0.01}$ (Katiyar et al. 2017). This suggests that more nitrogen than phosphorus is needed for the growth of the microalgae. As a result, no phosphorus source was added during the whole of the cultivation process in this study.

A stationary phase was observed around day 8 in the three mixotrophic groups. Of course, a possible reason for this restricted microalgal growth is that the microalgae was suffering from a nitrogen deficiency. Hence, large amounts of nitrogen were added to the MX and MX-C samples on day 9 (that is, at the beginning of the second phase) and the MX-N samples were not changed so they could act as a nitrogen-deficient control. Meanwhile, air aeration of the MX and MX-N groups was changed to $10 \% \mathrm{CO}_{2}$ aeration and the MX-C group was left unchanged to act as a $\mathrm{CO}_{2}$-deficient control.

As can be seen from Fig. 2b, aeration with a high concentration of $\mathrm{CO}_{2}(10 \%)$ lead to sharp decreases in the $\mathrm{pH}$ values of the MX and MX-N samples on day 10, and the acidic environment produced appears to have had a slightly inhibitory effect on the growth of the microalgae (Fig. 2a). Although the $\mathrm{pH}$ values of the MX-N samples tended to stabilize in subsequent days, nitrogen deficiency limited the growth of C. vulgaris (Table 2) in them. This lead to a $0.13 \mathrm{~g} \mathrm{~L}^{-1}$ decrement in the biomass in this group during the second cultivation stage compared to the end of Phase I (Table 3). Substantial growth, on the other hand, was observed in the MX samples (Fig. 2a) which may be attributed to the abundance of nutrient salts present.

Interestingly, both inorganic and organic carbon sources appear sufficient for the growth of $C$. vulgaris. The primary carbon source utilized for the growth of the algae was $\mathrm{CO}_{2}$ (TOC decreased by $\sim 57 \mathrm{mg} \mathrm{L}^{-1}$ [Table 2) while the biomass increased by $1790 \mathrm{mg} \mathrm{L}^{-1}$ (Table 3)]. That is to say, photoautotrophic growth was the major form of C. vulgaris growth in the MX samples during
Phase II. In contrast, the TOC fell by $\sim 406 \mathrm{mg} \mathrm{L}^{-1}$ in the MX-C group during the second stage while the biomass of the microalgae increased by just $400 \mathrm{mg} \mathrm{L}^{-1}$. This indicates that the $C$. vulgaris in the MX-C group was still growing via mixotrophy, even though enough $\mathrm{CO}_{2}$ was not being supplied-that is, the carbon source used for growth at this time was still the organic carbon.

The two possible pathways for TOC utilization in Phase II of the MX-C group could be: (i) the previously oxidized acidic intermediates were further oxidized to $\mathrm{CO}_{2}$ which was then released into the culture system and subsequently trapped/reused for photosynthesis; (ii) the intermediates are utilized directly by the $C$. vulgaris for heterotrophic growth; the $\mathrm{CO}_{2}$ released by the microalgae via aerobic respiration could be then utilized in the same way as in pathway (i) (Mata et al. 2010; Li et al. 2014). This could possibly explain why the TOC decrement exceeds the increment of carbon content in the biomass produced in MX-C. However, the relative importance of the two pathways needs to be studied further. On the whole, $\mathrm{CO}_{2}$-deficiency is an important limitation on the further growth of $C$. vulgaris in the MX-C group of samples even though an abundant source of nitrogen was available.

One of the aims of our study was to take advantage of the mixotrophic growth of $C$. vulgaris in the first stage of the procedure to obtain a high biomass concentration in a short time and then permit the microalgae to bio-fix much more of the $\mathrm{CO}_{2}$ available in the second stage. This goal was clearly achieved as the increase in biomass concentration in MX in Phase II within 8 days was higher than the biomass increment in the PA group during the whole of its period of cultivation (1790 vs. $1210 \mathrm{mg} \mathrm{L}^{-1}$, see Table 3). However, it is difficult, in general, to calculate the rate of $\mathrm{CO}_{2}$ bio-fixation during mixotrophic cultivation. The determination result shows that the carbon content of the C. vulgaris is $50.4 \%$. Assuming that all of the TOC decrement is utilized for C. vulgaris growth, then, for Phase II of the MX samples, the rate of bio-fixation of $\mathrm{CO}_{2}$ by $C$. vulgaris must be at least $344 \mathrm{mg} \mathrm{CO}_{2} \mathrm{~L}^{-1}$ day $^{-1}$. This is roughly 1.8 times that occurring in PA during the whole of its cultivation period $\left(124 \mathrm{mg} \mathrm{CO}_{2} \mathrm{~L}^{-1}\right.$ day $\left.^{-1}\right)$. Consequently, the two-stage mixotrophic cultivation process is an effective way of obtaining a high biomass concentration of $C$. vulgaris and improving its $\mathrm{CO}_{2}$ bio-fixation rate.

We further note that microalgal lipid accumulation and production during these kinds of two-stage cultivation procedures has rarely been investigated. Cheirsilp and Torpee (2012) found that the lipid content of four microalgal strains did not differ significantly using three different cultivation modes (although the growth of all strains was improved under mixotrophic conditions). This conclusion can also be drawn from the present study as the lipid content of the 4 groups ranged from 20.19 to 
$24.63 \%$. The maximum lipid content was observed in the photoautotrophic group, in agreement with the results reported by Liang et al. (2009) and Heredia-Arroyo et al. (2011) who also focused on C. vulgaris. Interestingly, N limitation in MX-N groups hasn't improved the lipid synthesis dramatically compared to $\mathrm{N}$ replete groups (MX) (Table 3) as many previous studies reported (Deng et al. 2011; Mujtaba et al. 2012). However, many microalgae species have been found to obtain higher lipid contents at $\mathrm{N}$ replete instead of $\mathrm{N}$ deplete conditions. Feng et al. (2011) reported the same results, C. pyrenoidosa had the maximum lipid content and productivity under the $\mathrm{N}$ replete medium rather than $\mathrm{N}$ deplete medium. And the reason was owing to the enhanced activity of acetyl-CoA carboxylase or other key enzymes related to the conversion of poly saccharides into lipids (Feng et al. 2011; Bellou et al. 2014). According to the investigation by Griffiths and Harrison (2009), 17 of 24 different microalgal species showed lipid accumulation under $\mathrm{N}$ deplete conditions while the others showed an increase of lipid content under $\mathrm{N}$ deplete conditions. So it is thought that the responses of algal cells to nitrogen deplete/replete conditions are species-specific as well as an intrinsic characteristic (Kim et al. 2016). And maybe the same reason could be used to explain this interesting result in the present study. Futhermore, the two-stage, nutrientsupplemented, mixotrophic cultivation process (group MX) showed the highest levels of lipid production and productivity (786.60 $\mathrm{mg} \mathrm{L}^{-1}$ and $43.70 \mathrm{mg} \mathrm{L}^{-1}$ day $^{-1}$, see Table 3). This implies that two-stage mixotrophic cultivation is also a highly efficient way of improving the quantity of lipids produced.

The fuel properties of biodiesel are strongly influenced by the properties of the individual fatty esters in biodiesel. PUFAs were observed in all three of the mixotrophic groups (Table 4). This is presumably because the added $\mathrm{NaE}$, a deoxidant, prevented the PUFAs from being oxidized to MUFAs. The increase in PUFA concentration can reduce the viscosity, leading to better lubricity compared to saturated fatty acids (Serrano et al. 2014). This can enhance cold flow performance due to the fact that the presence of unsaturated FAs retards the crystallization process at low temperature (Kim et al. 2016). Although relatively high levels of PUFAs would affect the oxidative stability, since the oxidation rates of $\mathrm{C} 16: 2$, C16:3 and C18:2, C18:3 are higher compared to those of C16:1 and C18:1. The problems can be solved by adding antioxidants, such as $\mathrm{NaE}$ present in this study. That C16 and C18 account for the majority of the carbon chain lengths featuring in the FAs is in accord with other results reported in the literature and suggests that the main FAs present in the lipids derived from Chlorella sp. are essentially short-chain FAs (C14-C18) (Huang et al.
2010). In the present study, over $60-68 \%$ of the lipids produced consist of TSFAs and MUFAs, which are considered to be suitable for synthesizing biodiesel (Sheehan et al. 1998). Hence, the two-stage mixotrophic cultivation process also seems to be a highly suitable way of generating biodiesel feedstock using $C$. vulgaris.

Moreover, linolenic and linoleic acids are known to be essential FAs and are an obligatory dietary requirement for humans and animals alike (Sinclair 1990). Most humans have diets that are deficient in linolenic acids and PUFAs are in great demand as dietary supplements and also for aquaculture. Therefore, microalgal oils derived via two-stage mixotrophic cultivation may be an excellent source of such high-value products.

\section{Authors' contributions}

$\mathrm{HC}$ and FM conceived and designed the study. HC, FL, YW, WD and YL performed the experiments. HC wrote the paper. $\mathrm{HC}$ and FM reviewed and edited the manuscript. All authors read and approved the final manuscript.

\section{Author details}

1 Key Laboratory of Marine Environment and Ecology, Ministry of Education, Ocean University of China, Qingdao 266100, Shandong Province, China.

${ }^{2}$ National Ocean Technology Center, Tianjin 300112, China. ${ }^{3}$ Department of Environmental Science and Engineering, Ocean University of China, No. 238, Songling Road, Qingdao 266100, China.

\section{Acknowledgements}

Authors acknowledge language editor I. D. Hands who provided professional writing services from Zhengzhou Yuwen education consulting co. LTD.

\section{Competing interests}

The authors declare that they have no competing of interests.

Availability of data and materials

No deposit of data is required for this article.

\section{Consent for publication}

Not applicable.

Ethics approval and consent to participate

Not applicable.

\section{Funding}

This work was supported by The Chinese National 'Twelfth Five-Year' Plan for Science \& Technology Support for Projects [Grant Number 2011BAD14B04].

\section{Publisher's Note}

Springer Nature remains neutral with regard to jurisdictional claims in published maps and institutional affiliations.

Received: 20 September 2017 Accepted: 28 September 2017 Published online: 10 October 2017

\footnotetext{
References

Bellou S, Baeshen MN, Elazzazy AM, Aggeli D, Sayegh F, Aggelis G (2014) Microalgal lipids biochemistry and biotechnological perspectives. Biotechnol Adv 32:1476-1493. doi:10.1016/j.biotechadv.2014.10.003

Bhatnagar A, Bhatnagar M, Chinnasamy S, Das KC (2010) Chlorella minutissimada promising fuel alga for cultivation in municipal wastewaters. Appl Biochem Biotechnol 161:523-536. doi:10.1007/s12010-009-8771-0

Bingh EG, Dyer WJ (1959) A rapid method of total lipid extraction and purification. Can J Biochem Physiol 37:911-917. doi:10.1139/y59-099
} 
Cheirsilp B, Torpee S (2012) Enhanced growth and lipid production of microalgae under mixotrophic culture condition: effect of light intensity, glucose concentration and fed-batch cultivation. Bioresour Technol 110:510-516. doi:10.1016/j.biortech.2012.01.125

Chen CY, Yeh KL, Aisyah R, Lee DJ, Chang JS (2011) Cultivation, photobioreactor design and harvesting of microalgae for biodiesel production: a critical review. Bioresour Technol 102:71-81. doi:10.1016/j.biortech.2010.06.159

Cheng J, Huang Y, Feng J, Sun J, Zhou JH, Cen KF (2013) Mutate Chlorella sp. by nuclear irradiation to fix high concentrations of CO2. Bioresour Technol 136:496-501. doi:10.1016/j.biortech.2013.03.072

Cui HW, Meng FP, Li F, Wang YJ (2017) Application of sodium erythorbate to promote the growth of Chlorella vulgaris. J Appl Phycol 3:1135-1144. doi:10.1007/s10811-016-1021-2

Deng X, Fei X, Li Y (2011) The effects of nutritional restriction on neutral lipid accumulation in Chlamydomonas and Chlorella. Afr J Microbiol Res 5:260-270. doi:10.5897/AJMR10.557

Earth System Research Laboratory (2017) Global Monitoring Division. Recent Global $\mathrm{CO}_{2}$. https://www.esrl.noaa.gov/gmd/ccgg/trends/global.html. Accessed 5 June 2017

Feng DN, Chen ZA, Xue S, Zhang W (2011) Increased lipid production of the marine oleaginous microalgae Isochrysis zhangjiangensis (Chrysophyta) by nitrogen supplement. Bioresour Technol 102:6710-6716. doi:10.1016/j. biortech.2011.04.006

Griffiths MJ, Harrison STL (2009) Lipid productivity as a key characteristic for choosing algal species for biodiesel production. J Appl Phycol 21:493-507. doi:10.1007/s10811-008-9392-7

Heredia-Arroyo T, Wei W, Ruan R, Hu B (2011) Mixotrophic cultivation of Chlorella vulgaris and its potential application for the oil accumulation from non-sugar materials. Biomass Bioenerg 35:2245-2253. doi:10.1016/j. biombioe.2011.02.036

Huang GH, Chen F, Wei D, Zhang XW, Chen G (2010) Biodiesel production by microalgal biotechnology. Appl Energy 87:38-46. doi:10.1016/j. apenergy.2009.06.016

Huerlimann R, de Nys R, Heimann K (2010) Growth, lipid content, productivity, and fatty acid composition of tropical microalgae for scale-up production. Biotechnol Bioeng 107:245-257. doi:10.1002/bit.22809

Kaiwan-arporn P, Hai PD, Thu NT, Annachhatre AP (2012) Cultivation of cyanobacteria for extraction of lipids. Biomass Bioenerg 44:142-149. doi:10.1016/j.biombioe.2012.04.017

Kang RJ, Wang J, Shi DJ, Cong W, Cai ZL, Ouyang F (2004) Interactions between organic and inorganic carbon sources during mixotrophic cultivation of Synechococcus sp. Biotechnol Lett 26:1429-1432. doi:10.1023/ B:BILE.0000045646.23832.a5

Katiyar R, Gurjar BR, Biswas S, Pruthi V, Kumar N, Kumar P (2017) Microalgae: an emerging source of energy based bio-products and a solution for environmental issues. Renew Sust Energ Rev 72:1083-1093. doi:10.1016/j. rser.2016.10.028

Kebelmann K, Hornung A, Karsten U, Griffiths G (2013) Intermediate pyrolysis and product identification by TGA and Py-GC/MS of green microalgae and their extracted protein and lipid components. Biomass Bioenerg 49:38-48. doi:10.1016/j.biombioe.2012.12.006

Kim G, Bae J, Lee K (2016) Nitrate repletion strategy for enhancing lipid production from marine microalga Tetraselmis sp. Bioresour Technol 205:274-279. doi:10.1016/j.biortech.2016.01.045

Li T, Zheng YB, Yu L, Chen SL (2014) Mixotrophic cultivation of a Chlorella sorokiniana strain for enhanced biomass and lipid production. Biomass Bioenerg 66:204-213. doi:10.1016/j.biombioe.2014.04.010

Liang Y, Sarkany N, Cui Y (2009) Biomass and lipid productivities of Chlorella vulgaris under autotrophic, heterotrophic and mixotrophic growth conditions. Biotechnol Lett 31:1043-1049. doi:10.1007/s10529-009-9975-7

Mata TM, Martins AA, Caetano NS (2010) Microalgae for biodiesel production and other applications: a review. Renew Sust Energ Rev 14:217-232. doi:10.1016/j.rser.2009.07.020

Mujtaba G, Choi W, Lee CG, Lee K (2012) Lipid production by Chlorella vulgaris after a shift from nutrient-rich to nitrogen starvation conditions. Bioresour Technol 123:279-283. doi:10.1016/j.biortech.2012.07.057

Najafabadi HA, Malekzadeh M, Jalilian F, Vossoughi M, Pazuki G (2015) Effect of various carbon sources on biomass and lipid production of Chlorella vulgaris during nutrient sufficient and nitrogen starvation conditions. Bioresour Technol 180:311-317. doi:10.1016/j.biortech.2014.12.076
Park KC, Whitney C, McNichol JC, Dickinson KE, MacQuarrie S, Skrupski BP, Zou JT, Wilson KE, O'Leary SJB, McGinn PJ (2012) Mixotrophic and photoautotrophic cultivation of 14 microalgae isolates from Saskatchewan, Canada: potential applications for wastewater remediation for biofuel production. J Appl Phycol 24:339-348. doi:10.1007/s10811-011-9772-2

Procházková G, Brányiková I, Zachleder V, Brányik T (2014) Effect of nutrient supply status on biomass composition of eukaryotic green microalgae. J Appl Phycol 26:1359-1377. doi:10.1007/s10811-013-0154-9

Rawat I, Ranjith Kumar R, Mutanda T, Bux F (2013) Biodiesel from microalgae: a critical evaluation from laboratory to large scale production. Appl Energ 103:444-467. doi:10.1016/j.apenergy.2012.10.004

Serrano M, Oliveros R, Sanchez M, Moraschini A, Martinez M, Aracil J (2014) Influence of blending vegetable oil methyl esters on biodiesel fuel properties: oxidative stability and cold flow properties. Energy 65:109-115. doi:10.1016/j.energy.2013.11.072

Sheehan J, Dunahay T, Benemann J, Roessler PA (1998) Look back at the US Department of Energy's Aquatic Species Program: biodiesel from algae. National Renewable Energy, Laboratory, p 328

Sinclair HM (1990) Essential fatty acids - a historical perspective. Biochem Soc T 18:756-761. doi:10.1042/bst0180756

Toledo-Cervantes A, Morales M, Novelo E, Revah S (2013) Carbon dioxide fixation and lipid storage by Scenedesmus obtusiusculus. Bioresour Technol 130:652-658. doi:10.1016/j.biortech.2012.12.081

Wang B, Li Y, Wu N, Lan CQ (2008) $\mathrm{CO}_{2}$ bio-mitigation using microalgae. Appl Microbiol Biot 79:707-718. doi:10.1007/s00253-008-1518-y

Wilbanks TJ, Fernandez S (2014) Climate change and infrastructure, urban systems, and vulnerabilities: technical report for the US Department of Energy in Support of the National Climate Assessment. Island Press, Washington

Xu J, Zhao Y, Zhao G, Zhang H (2015) Nutrient removal and biogas upgrading by integrating freshwater algae cultivation with piggery anaerobic digestate liquid treatment. Appl Microbiol Biotechnol 99:6493-6501. doi:10.1007/s00253-015-6537-x

Yeh KL, Chang JS (2012) Effects of cultivation conditions and media composition on cell growth and lipid productivity of indigenous microalga Chlorella vulgaris ESP-31. Bioresour Technol 105:120-127. doi:10.1016/j. biortech.2011.11.103

Yen HW, Chang JT (2013) A two-stage cultivation process for the growth enhancement of Chlorella vulgaris. Bioproc Biosyst Eng 36:1797-1801. doi:10.1007/s00449-013-0922-6

Yen HW, Zhang Z (2011) Effects of dissolved oxygen level on cell growth and total lipid accumulation in the cultivation of Rhodotorula glutinis. J Biosci Bioeng 112:71-74. doi:10.1016/j.jbiosc.2011.03.013

Yilancioglu K, Cokol M, Pastirmaci I, Erman B, Cetiner S (2014) Oxidative stress is a mediator for increased lipid accumulation in a newly isolated Dunaliella salina strain. PLoS ONE 9:e91957. doi:10.1371/journal.pone.0091957

\section{Submit your manuscript to a SpringerOpen ${ }^{\circ}$ journal and benefit from:}

- Convenient online submission

- Rigorous peer review

- Open access: articles freely available online

- High visibility within the field

- Retaining the copyright to your article

Submit your next manuscript at $\boldsymbol{\nabla}$ springeropen.com 